\title{
Assessing Sociodemographic Predictors of Climate Change Concern, 1994-2016
}

\author{
Daniel Driscoll (D), University of California, San Diego
}

Objective. In this research note, I examine whether the growing influence of political orientation on climate change concern has resulted in the declining influence of the sociodemographic variables that have historically predicted such views. Methods. Utilizing evidence from the 1994, 2000, 2010, and 2016 General Social Surveys, I conduct ordered logit regressions, Wald significance tests, and partition the pseudo- $R^{2}$ across years to ensure consistency of findings. Results. A comparison across three decades reveals that while climate change concern was once grounded in sociodemographic predictors such as age, education, income, sex, race, or size of residential area, the explanatory power of those predictors has declined over time. Climate change concern is now better explained by political orientation variables; once modest in influence, only to rise in prominence over time. Conclusion. These findings are connected to political polarization and the "denial countermovement" and their impact on the American public. This article is the first to explicitly and systematically track the decline of sociodemographic predictors of climate change concern over time.

Who is concerned about climate change in the United States? This basic, but fundamental, question motivates a significant body of scholarship that examines beliefs, perceptions of risk, knowledge, and concern regarding anthropogenic climate change (Shwom et al., 2015). Due to an increase in the explanatory power of political variables in predicting who is concerned, a large subset of this work traces the politicization of climate change views, especially in the United States, but increasingly in other nations as well (McCright, Dunlap, and Marquart-Pyatt, 2016; Tranter, 2017). Environmental sociologists Riley Dunlap, Lawrence Hamilton, and Aaron McCright have made substantial contributions in this area, tracing the polarization between Democrats and Republicans on the issue of climate change (Dunlap and McCright, 2008; McCright and Dunlap, 2011; Dunlap, McCright, and Yarosh, 2016; Hamilton et al., 2015). Polarizations are not simply partisan; they are ideological as well (Hamilton and Saito, 2015; McCright and Dunlap, 2011). Equally important, scholars find that the political polarization gap between Democrats and Republicans is increasing (Dunlap, McCright, and Yarosh, 2016; McCright, Dunlap, and Xiao, 2014a; Shwom et al., 2015). In fact, polarization over the issue is so potent that the effects of political orientation override exposure to climate or weather extremes (Hamilton et al., 2015; Marquart-Pyatt et al., 2014; McCright, Dunlap, and Xiao, 2014b).

This article confirms that the political polarization gap has widened over time, using survey data spanning three decades (1994-2016). More importantly, it also tracks the declining significance of sociodemographic characteristics (age, education, income, sex,

Direct correspondence to Daniel Driscoll, Department of Sociology, University of California, San Diego, 401 Social Science Building, 9500 Gilman Drive, Dept. 0533, La Jolla, CA 92093-0533 〈drdrisco@ucsd.edu). I am grateful to Lane Kenworthy, who read multiple drafts and encouraged me to extend my thinking and analyses. I extend thanks to Isaac Martin for his methodological insights and clarifications. The data from this article are available from the General Social Survey. No potential conflict of interest to report. 
race, or residence size) in tandem with the rising significance of party identification and political ideology as predictors of views on climate change. These findings clarify the effects of the widening political polarization.

\section{The Denial Countermovement}

To understand the roots of polarization and why the explanatory power of sociodemographic predictors may be declining, it is important to consider the political context of the United States. Scholars have reached consensus that the denial countermovement plays a significant role in explaining both public views and the substantial polarization in the United States around the issue of climate change (McCright, Dunlap, and Marquart-Pyatt, 2016). Dunlap and McCright (2015) overview the underpinnings of climate change countermovements. They outline how historical and cultural factors such as the human-nature schism, the Industrial Revolution, neoliberalism, and conservative movements contribute to a conception of nature that is utilitarian and growth oriented. This historical orientation, they argue, fuels the forces that deny climate change because those forces defend the neoliberal state from challenges to its structure (Dunlap and McCright, 2015; McCright and Dunlap, 2010). This claim is supported by the fact that denial countermovements are found in other countries that have "strong commitments to neoliberalism and a powerful fossil fuels industry" (Dunlap and McCright, 2015:319).

What forces are at work in the denial countermovement and what are their impacts? Dunlap and McCright describe several: the fossil fuel industry and corporations, conservative think tanks and foundations, contrarian scientists, front groups and astroturf campaigns, conservative politicians, conservative mainstream media, and social media. Scholars find that corporate and foundation funding impacts the ways in which denial countermovement organizations represent climate change (Brulle, 2014; Farrell, 2016). For instance, influenced by the backing of the Koch brothers and other interests who deny climate change, the Tea Party included climate change denial in its platform (Dunlap, McCright, and Yarosh, 2016). In fact, scholars have found that political groups and elites are so influential that their ideological message outperforms other factors that impact concern, including weather extremes, scientific information, and economic factors (Carmichael and Brulle, 2017). The denial ideology promoted by these individuals and groups is typically disseminated through partisan media outlets. These media outlets create "echo chambers" where partisan views are reinforced and opposing views are dismissed (Carmichael, Brulle, and Huxster, 2017). Republicans and conservatives increasingly express skepticism about climate change (Dunlap, McCright, and Yarosh, 2016). This countermovement, along with political polarization, offers strong theoretical support for the declining explanatory power of sociodemographic predictors.

\section{Research Focus: Sociodemographic Variables}

Has the growing influence of political orientation on climate change concern resulted in the declining influence of the sociodemographic variables that have historically predicted such views? This is the research question addressed in this article.

Much previous research on political polarization treats sociodemographic variables simply as control variables, without assessing their effects over time. This is problematic for two reasons. First, the extent to which political orientation has come to overshadow the 
effects of sociodemographic variables over time is missed. Second, it may lead scholars to overcharacterize those who are concerned about climate change as belonging to particular sociodemographic categories based on outdated studies. It seems likely that the impact of membership in those categories may be lessening over time as political influences have outweighed the effects of sociodemographic variables.

A key focus of this article is the relative importance of two sets of explanatory variables, especially whether the effects of the sociodemographic variables remain significant after controlling for party identification and political ideology over a 22-year period. Based on the literature, I expect attitudes toward climate change to become increasingly divorced from their grounding in sociodemographic categories as the issue becomes more politicized over time. I test my hypothesis using evidence from the 1994, 2000, 2010, and 2016 General Social Surveys, which contain an attitudinal question about climate change. Using Stata's ordered logit analysis, I analyze the connection between various sociodemographic variables such as sex, race, education, income, residence size, and age, on the one hand, and concern for climate change, on the other hand. A focus on these specific sociodemographic variables is supported by past studies showing they are related to views regarding climate change (Hamilton, 2011; Liu, Vedlitz, and Shi, 2014; McCright, Dunlap, and MarquartPyatt, 2016; McCright and Dunlap, 2011; Shwom et al., 2015).

In the statistical analysis that follows I assess the impact of these sociodemographic variables over multiple points in time, while controlling for the influence of political party identity and political ideology. Because sociodemographic characteristics are linked to political orientation, it is important to assess their effects controlling for the effects of the political party identification and political ideology variables.

\section{Data and Methods}

Hypothesis: I expect the explanatory power of sociodemographic variables to decrease over time, whereas the explanatory power of political orientation variables increases.

In order to test this hypothesis, I utilize data from the 1994, 2000, 2010, and 2016 General Social Surveys. The GSS is a nationally representative sample and considered to be one of the highest quality surveys. ${ }^{1}$ The data sets contain a response variable concerning climate change that is of specific interest to environmental sociologists. In this article, the response variable is based on the following GSS question: ${ }^{2}$

In general, do you think that a rise in the world's temperature caused by the "greenhouse effect" is...

1 Extremely dangerous for the environment

2 Very dangerous

3 Somewhat dangerous

4 Not very dangerous

5 Not dangerous at all for the environment

8 Don't know

\footnotetext{
1 "It is the only full-probability, personal-interview survey designed to monitor changes in both social characteristics and attitudes currently being conducted in the United States" (GSS). For this reason, this data set is especially valuable for assessing the sources of variation in concern about climate change.

${ }^{2}$ Though the question appears to have a slight confirming bias, climate skeptics and those undecided are provided a range of confirming, equivocal, or denying responses.
} 
9 No answer

0 Not applicable

In 2010, NORC used the words "climate change" instead of "greenhouse effect." Most studies that examine survey terminology look at differences in how subjects respond to "climate change" versus "global warming." Results are mixed, finding modest or no differences between the two terms (Shwom et al., 2015). However, Republicans often respond less favorably to "global warming" than to "climate change" (Schuldt, Konrath, and Schwarz, 2011; Suhay et al., 2015; Villar and Krosnick, 2011). Recent analysis reveals that both Democrats and Republicans react similarly to both terms, supporting the impact of increasing polarization, regardless of terminology (Dunlap, 2014).

For my analysis, I removed response categories 8, 9, and 0 because these responses are irrelevant to the concept underlying my response variable. I also reverse coded the variable so that high scores indicate more concern for the environment. ${ }^{3}$ The explanatory variables tested from the data set were sex, age, race, education, income, residence size, party identification, and political ideology. Table 1 describes coding strategies for explanatory variables.

Utilizing Stata, I conducted an ordered logit analysis with the response variable regressed on the sociodemographic and political variables. I also regressed the response variable on the sociodemographic variables and the political orientation variables separately (see Supporting Information). This second analytic strategy permits assessment of the relative impact of the sociodemographic variables and the political orientation variables on the response variable.

\section{Results}

Table 2 reports the results of the ordered logit analyses. The most dramatic contrasts between surveys are the slope coefficients for party identification and political ideology. The coefficients in 1994 and 2000 are much weaker than the 2010 and 2016 coefficients. In 1994, the slope of party identification on climate change concern was -0.084 ; in 2000 , it was -0.098 ; in 2010, it was -0.259 ; and in 2016, it was -0.230 . In 1994, the slope of political ideology on climate change concern was -0.142 ; in 2000 , it was -0.141 ; in 2010 , it was -0.236; and in 2016, it was -0.409. In sum, from 1994 to 2016 the slopes of party identification and political orientation on climate change concern increased by more than 2.5 times.

The slope coefficients for the sociodemographic variables vary in strength across time. The coefficient for age remains stable from -0.018 in 1994 to -0.014 in 2016 . The coefficient for education declines in strength from 0.107 in 1994 to 0.076 in 2016. The coefficient for income declines in strength from -0.028 in 1994 to -0.005 in 2016 . The coefficient for sex declines in strength from -0.435 in 1994 to 0.030 in 2016. The coefficient for race changes sign from -0.300 in 1994 to 0.240 in 2016 . The coefficient for residence size remains stable from 0.00002 in 1994 to -0.00002 in 2016 .

The equations assess the significance of the sociodemographic variables while controlling for party identification and political ideology. In 1994, four sociodemographic variables are significant: age at $p<0.001$, education at $p<0.001$, income at $p<0.05$, and sex at $p<0.01$. Party identification and political ideology are significant at $p<0.05$ and

\footnotetext{
${ }^{3}$ This modification to the response variable is intuitively helpful because the higher the number, the greater the concern for climate change. Reversing the scale makes data analysis more intuitive.
} 
TABLE 1

Variables and Coding

\begin{tabular}{|c|c|}
\hline Explanatory Variable & Description \\
\hline Age & $\begin{array}{l}18 \text { to } 80 \\
\text { Mean: } 40.5(1994), 40.6(2000), 43.4(2010), 44.7(2016) \\
\text { Standard deviation: } 12.57(1994), 12.67(2000), 14.47(2010), \\
\quad 13.72(2016)\end{array}$ \\
\hline Education & $\begin{array}{l}0 \text { to } 20 \\
\text { Mean: } 13.9 \text { (1994), } 13.9(2000), 13.92(2010), 14.26(2016) \\
\text { Standard deviation: } 2.57(1994), 2.65(2000), 2.88 \text { (2010), } 2.59 \\
\quad(2016)\end{array}$ \\
\hline Income & $\begin{array}{l}\text { Twenty-five ordinal income categories (with } 1 \text { the lowest and } \\
25 \text { the highest); the variable was treated as continuous } \\
\text { Mean: } 12.46 \text { (1994), } 13.49(2000), 13.8(2010), 15.62(2016) \\
\text { Standard deviation: } 5.15 \text { (1994), } 5.50 \text { (2000), } 6.37 \text { (2010), } 6.14 \\
\quad(2016)\end{array}$ \\
\hline Sex (male) & $\begin{array}{l}1=\text { male and } 0=\text { female } \\
\text { Mean: } 0.50(1994), 0.51(2000), 0.447(2010), 0.47(2016) \\
\text { Standard deviation: } 0.50(1994), 0.50(2000), 0.497(2010) \\
\quad 0.499(2016)\end{array}$ \\
\hline Race (white) & $\begin{array}{l}1=\text { white and } 0=\text { nonwhite } \\
\text { Mean: } 0.847(1994), 0.80(2000), 0.758(2010), 0.722(2016) \\
\text { Standard deviation: } 0.359(1994), 0.397(2000), 0.428(2010) \\
\quad 0.448(2016)\end{array}$ \\
\hline Residence size & $\begin{array}{l}\text { Size of respondent's residential area in 1,000s. } \\
\text { Mean: } 283.9 \text { (1994), } 299.2(2000), 364.0(2010), 371.3(2016) \\
\text { Standard deviation: } 993.3(1994), 1050.9 \text { (2000), } 1245.8 \\
\quad(2010), 1130.0(2016)\end{array}$ \\
\hline Party identification & $\begin{array}{l}\text { Political party identification on a scale from (1) strong } \\
\quad \text { Democrat to (6) strong Republican } \\
\text { Mean: } 2.95 \text { (1994), } 2.98 \text { (2000), } 2.67 \text { (2010), } 2.69 \text { (2016) } \\
\text { Standard deviation: } 2.0 \text { (1994), } 1.94 \text { (2000), } 1.97 \text { (2010), } 1.94 \\
\quad(2016)\end{array}$ \\
\hline Political ideology & $\begin{array}{l}\text { Political ideology on a scale from (1) extremely liberal to (7) } \\
\quad \text { extremely conservative } \\
\text { Mean: } 4.14(1994), 4.17(2000), 4.03(2010), 4.02(2016) \\
\text { Standard deviation: } 1.39(1994), 1.41(2000), 1.44(2010), 1.48 \\
\quad(2016)\end{array}$ \\
\hline
\end{tabular}

$p<0.01$, respectively. In 2000, two sociodemographic variables are significant: age at $p<$ 0.01 and residence size at $p<0.001$. Party identification and political ideology are both significant at $p<0.05$. In 2010, one sociodemographic variable is significant: residence size at $p<0.05$. Party identification and political ideology are both significant at $p<0.001$. In 2016, two sociodemographic variables are significant: age at $p<0.05$ and education at $p<0.05$. Party identification and political ideology are both significant at $p<0.001$.

I also conducted two tests to ensure consistency of findings. First, I utilized Wald significance tests for the two sets of variables considered as blocks (see Supporting Information Table 5). The sociodemographic block (age, education, income, sex, race, and residence size) declines in significance over time, from $p<0.001$ in 1994 and 2000 to $p>0.05$ (not significant) in 2016. The political orientation block (party identification and political views) remains significant at $p<0.001$ across the four points in time. 
TABLE 2

1994, 2000, 2010, 2016 Coefficients for Ordered Logit Analysis of Climate Change Concern on Age, Education, Income, Sex, Race, Residence Size, Party Identification, and Political Ideology

\begin{tabular}{lcccc}
\hline Variables & 1994 & 2000 & 2010 & 2016 \\
\hline Age & $-0.018^{* * *}$ & $-0.018^{* *}$ & -0.002 & $-0.014^{*}$ \\
& $(0.005)$ & $(0.006)$ & $(0.005)$ & $(0.006)$ \\
Education & $0.107^{* * *}$ & 0.008 & -0.018 & $0.076^{*}$ \\
& $(0.028)$ & $(0.029)$ & $(0.026)$ & $(0.035)$ \\
Income & $-0.028^{*}$ & 0.008 & -0.022 & -0.005 \\
& $(0.014)$ & $(0.014)$ & $(0.012)$ & $(0.015)$ \\
Sex & $-0.435^{* *}$ & -0.018 & -0.192 & 0.030 \\
& $(0.139)$ & $(0.148)$ & $(0.140)$ & $(0.177)$ \\
Race & -0.300 & -0.143 & -0.180 & 0.240 \\
& $(0.187)$ & $(0.191)$ & $(0.168)$ & $(0.202)$ \\
Residence size & 0.00002 & $0.0002^{* * *}$ & $0.0001^{*}$ & -0.00002 \\
& $(0.00006)$ & $(0.00008)$ & $(0.00005)$ & $(0.00008)$ \\
Party identification & $-0.084^{*}$ & $-0.098^{*}$ & $-0.259^{* * *}$ & $-0.230^{* * *}$ \\
& $(0.038)$ & $(0.044)$ & $(0.044)$ & $(0.057)$ \\
Political ideology & $-0.142^{* *}$ & $-0.141^{*}$ & $-0.236^{* * *}$ & $-0.409^{* * *}$ \\
Pseudo- $R^{2}$ & $(0.054)$ & $(0.058)$ & $(0.057)$ & $(0.076)$ \\
$N$ & 0.037 & 0.030 & 0.0678 & 0.086 \\
& 782 & 688 & 746 & 472 \\
\hline
\end{tabular}

NotE: Numbers in parentheses are standard errors. I used list-wise deletion of cases with missing data for all three models.

${ }^{*} p<0.05,{ }^{* *} p<0.01,{ }^{* * *} p<0.001$

SOURCE: General Social Survey, 1994, 2000, 2010, 2016.

Second, I partitioned the pseudo- $R^{2}$ (McFadden's throughout) between the two sets of variables (see Supporting Information Table 6). I calculated the pseudo- $R^{2}$ of the sociodemographic and political orientation sets of variables separately. Then I assessed their degree of overlap by subtracting the combined pseudo- $R^{2}$ values from the sum of sociodemographic and political orientation pseudo- $R^{2}$ values. Next, I subtracted the overlap of the pseudo- $R^{2}$ values from the two sets of variables considered separately. This allows me to isolate the explanatory effects of the political orientation and sociodemographic variables. There is a dramatic difference in the explanatory power of the two sets of variables over time. The pseudo- $R^{2}$ specific to sociodemographic variables declined from 0.023 to 0.008 , while the pseudo- $R^{2}$ specific to political orientation variables increased from 0.01 to 0.07 .

\section{Discussion}

In "Explaining Public Views About Climate Change in the United States," McCright, Dunlap, and Marquart-Pyatt (2016) summarize the findings of 87 studies on climate change. They find that sociodemographic variables have inconsistent effects on climate change concern in various studies, and it is true that the estimates of the effects of sociodemographic variables in many prominent studies on climate change concern vary greatly (Dunlap and McCright, 2008; Hamilton, 2011; Liu, Vedlitz, and Shi, 2014; McCright and Dunlap, 2011; Shwom et al., 2015). In this study, not only are the individual effects of sociodemographic variables inconsistent over time, but there is also a general pattern of their declining strength over time (the main contribution of this study). Figures 1 
FIGURE 1

Coefficients of Political Orientation Variables Over Time

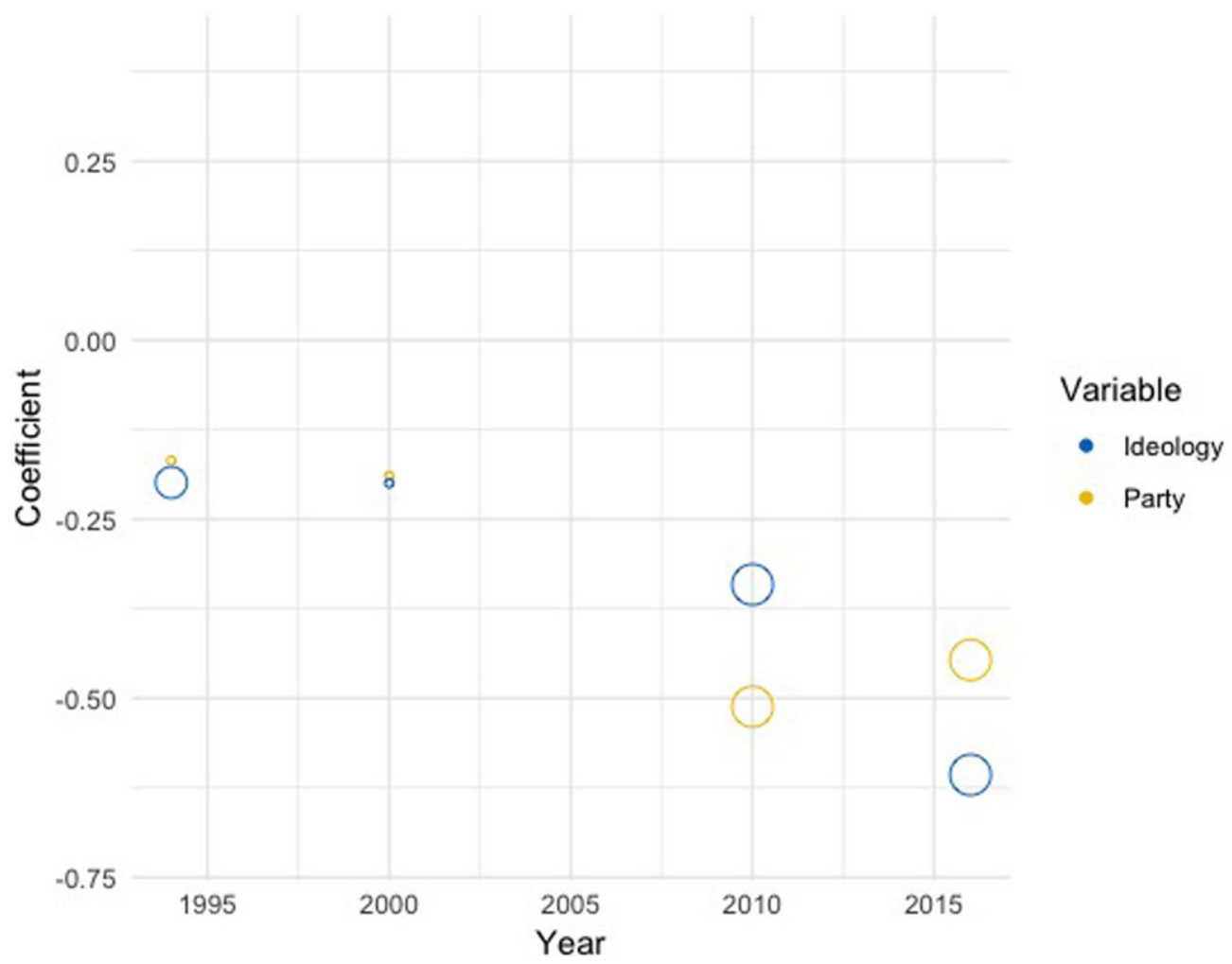

and 2 display the coefficients from the four surveys over time. The independent variables were converted to $z$-scores to enable comparison of the coefficients. The coefficients for the sociodemographic predictors are inconsistent and decrease in explanatory power over time. The coefficients for the political orientation predictors increase in absolute size and explanatory power over time.

The significance test and partitioning of the pseudo- $R^{2}$ support this trend. The block of political variables remains significant over time, while the block of sociodemographic variables declines in significance. When the political orientation variables were controlled for in the 1994 ordered logit analysis, four sociodemographic variables (age [0.001], education [0.001], sex [0.01], and income [0.05]) remained significant predictors of climate change concern. However, when the political orientation variables were controlled for in the 2016 ordered logit analysis, only two (age and education) remained significant predictors of climate change concern, both at the 0.05 level. These findings suggest that while sociodemographic variables influenced climate change concern in the past, their influence clearly has waned. It is likely that political polarization and the denial countermovement in the United States drove political orientation variables to prominence, outweighing sociodemographic predictors. While these findings are not definitive and based on four different surveys, they are consistent with hypotheses and invite further research. 


\section{FIGURE 2}

Coefficients of Sociodemographic Variables Over Time

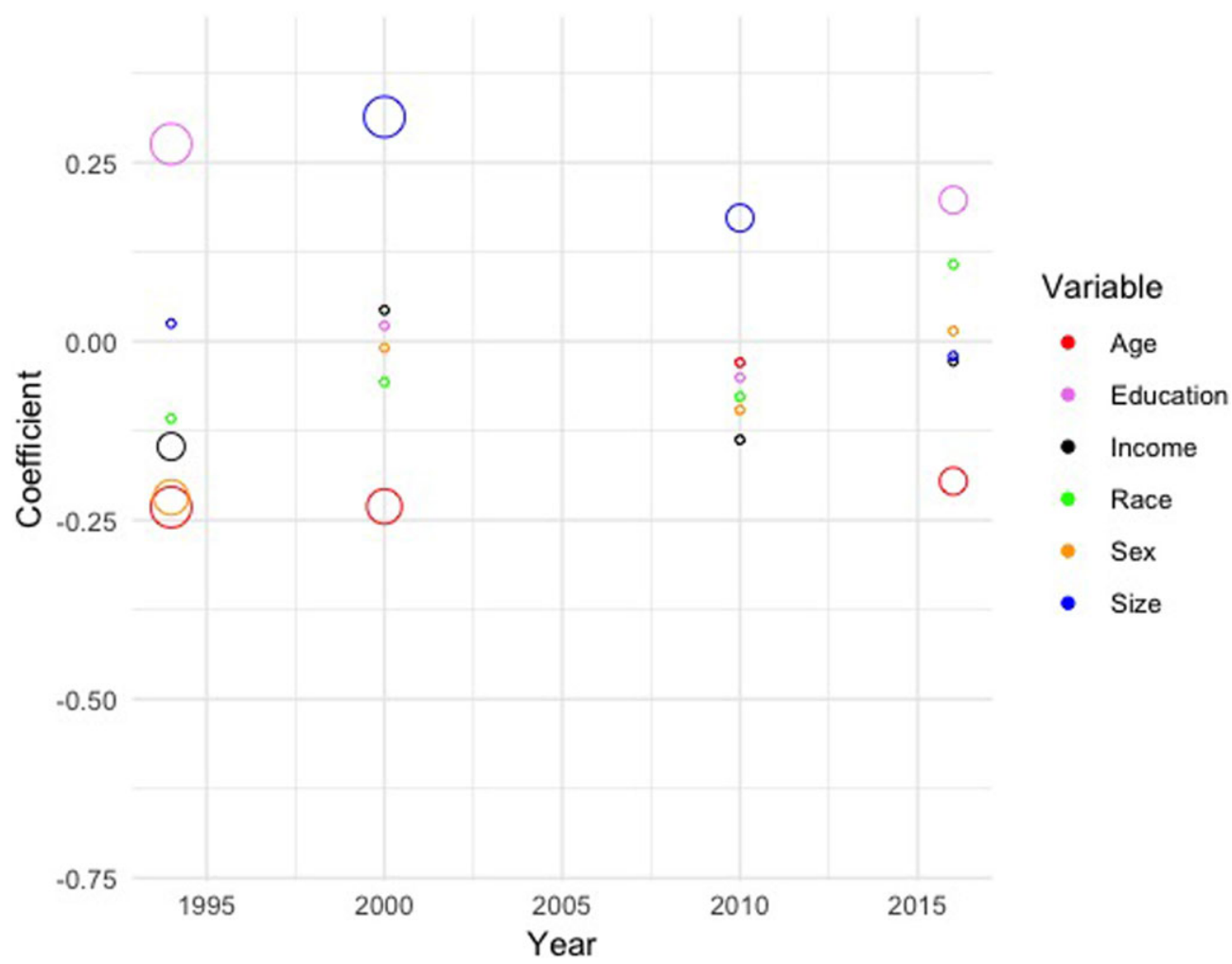

In sum, I conducted ordered logit analyses on the 1994, 2000, 2010, and 2016 GSS data sets to trace the decline of sociodemographic predictors of concern about climate change. My hypothesis, predicting that the growth of political polarization would be accompanied by the declining significance of sociodemographic predictors of climate change, was supported. This indicates that the intensely polarized nature of the contemporary United States has led to party identification and political ideology becoming the overwhelming determinants of individuals' views of many issues, overriding sociodemographic cleavages.

\section{REFERENCES}

Brulle, Robert J. 2014. "Institutionalizing Delay: Foundation Funding and the Creation of U.S. Climate Change Counter-Movement Organizations." Climatic Change 122(4):681-94.

Carmichael, Jason T., and Robert J. Brulle. 2017. “Elite Cues, Media Coverage, and Public Concern: An Integrated Path Analysis of Public Opinion on Climate Change, 2001-2013.” Environmental Politics 26(2):232-52.

Carmichael, Jason T., Robert J. Brulle, and Joanna K. Huxster. 2017. “The Great Divide: Understanding the Role of Media and Other Drivers of the Partisan Divide in Public Concern Over Climate Change in the USA, 2001-2014.” Climatic Change 141(4):599-612.

Dunlap, Riley E. 2014. “Global Warming or Climate Change: Is There a Difference?” Gallup.Com. Available at $\langle$ http://www.gallup.com/poll/168617/global-warming-climate-change-difference.aspx $\rangle$. 
Dunlap, Riley E., and Araon M. McCright. 2008. "A Widening Gap: Republican and Democratic Views on Climate Change." Environment: Science and Policy for Sustainable Development 50(5):26-35.

- 2015. "Challenging Climate Change: The Denial Countermovement." Pp. 300-32 in Riley E. Dunlap and Robert J. Brulle, eds., Climate Change and Society: Sociological Perspectives. New York: Oxford University Press.

Dunlap, Riley E., Aaron M. McCright, and Jerrod H. Yarosh. 2016. "The Political Divide on Climate Change: Partisan Polarization Widens in the U.S." Environment: Science and Policy for Sustainable Development 58(5):4-23.

Farrell, Justin. 2016. “Corporate Funding and Ideological Polarization About Climate Change.” Proceedings of the National Academy of Sciences 113(1):92-97.

Hamilton, Lawrence C. 2011. "Education, Politics and Opinions About Climate Change: Evidence for Interaction Effects." Climatic Change 104(2):231-42.

Hamilton, Lawrence C., Joel Hartter, Mary Lemcke-Stampone, David W. Moore, and Thomas G. Safford. 2015. "Tracking Public Beliefs About Anthropogenic Climate Change.” PLOS ONE 10(9):e0138208.

Hamilton, Lawrence C., and Kei Saito. 2015. “A Four-Party View of US Environmental Concern.” Environmental Politics 24(2):212-27.

Liu, Xinsheng, Arnold Vedlitz, and Liu Shi. 2014. "Examining the Determinants of Public Environmental Concern: Evidence from National Public Surveys." Environmental Science \& Policy 39:77-94.

Marquart-Pyatt, Sandra T., Aaron M. McCright, Thomas Dietz, and Riley E. Dunlap. 2014. "Politics Eclipses Climate Extremes for Climate Change Perceptions." Global Environmental Change 29:246-57.

McCright, Aaron M., and Riley E. Dunlap. 2010. “Anti-Reflexivity.” Theory, Culture \& Society 27(2-3): $100-33$.

- 2011. "The Politicization of Climate Change and Polarization in the American Public's Views of Global Warming, 2001-2010." Sociological Quarterly 52(2):155-94.

McCright, Aaron M., Riley E. Dunlap, and Sandra T. Marquart-Pyatt. 2016. "Political Ideology and Views About Climate Change in the European Union.” Environmental Politics 25(2):338-58.

McCright, Aaron M., Riley E. Dunlap, and Chenyang Xiao. 2014a. "Increasing Influence of Party Identification on Perceived Scientific Agreement and Support for Government Action on Climate Change in the United States, 2006-12." Weather, Climate, and Society 6(2):194-201.

. 2014b. "The Impacts of Temperature Anomalies and Political Orientation on Perceived Winter Warming." Nature Climate Change 4(12):1077-81.

McCright, Aaron M., Sandra T. Marquart-Pyatt, Rachael L. Shwom, Steven R. Brechin, and Summer Allen. 2016. "Ideology, Capitalism, and Climate: Explaining Public Views About Climate Change in the United States." Energy Research \& Social Science 21:180-89.

Schuldt, Jonathon P., Sara H. Konrath, and Norbert Schwarz. 2011. “Global Warming' or 'Climate Change'? Whether the Planet Is Warming Depends on Question Wording.” Public Opinion Quarterly 75(1):115-24.

Shwom, Rachael L., Aaron M. McCright, Steven R. Brechin, Riley E. Dunlap, Sandra T. Marquart-Pyatt, and Lawrence C. Hamilton. 2015. "Public Opinion on Climate Change." Pp. 269-99 in Riley E. Dunlap and Robert J. Brulle, eds., Climate Change and Society: Sociological Perspectives. New York: Oxford University Press.

Suhay, Elizabeth, James N. Druckman, Jonathon P. Schuldt, Sungjong Roh, and Norbert Schwarz. 2015. "Questionnaire Design Effects in Climate Change Surveys: Implications for the Partisan Divide." ANNALS of the American Academy of Political and Social Science 658(1):67-85.

Tranter, Bruce. 2017. "It's Only Natural: Conservatives and Climate Change in Australia." Environmental Sociology 3(3):274-85.

Villar, Ana, and Jon A. Krosnick. 2011. "Global Warming vs. Climate Change, Taxes vs. Prices: Does Word Choice Matter?” Climatic Change 105(1-2):1-12. 


\section{Supporting Information}

Additional supporting information may be found online in the Supporting Information section at the end of the article.

Table S1. 1994 Coefficients for Ordered Logit Analysis of Climate Change Concern on Age, Education, Income, Sex, Race, Residence Size, Party Identification, and Political Ideology

Table S2. 2000 Coefficients for Ordered Logit Analysis of Climate Change Concern on Age, Education, Income, Sex, Race, Residence Size, Party Identification, and Political Ideology

Table S3. 2010 Coefficients for Ordered Logit Analysis of Climate Change Concern on Age, Education, Income, Sex, Race, Residence Size, Party Identification, and Political Ideology

Table S4. 2016 Coefficients for Ordered Logit Analysis of Climate Change Concern on Age, Education, Income, Sex, Race, Residence Size, Party Identification, and Political Ideology

Table S5. Wald Significance Test of Sociodemographic and Political Orientation Variables Table S6. Partitioning McFadden's Pseudo- $R^{2}$ Between Sociodemographic and Political Orientation Variables 